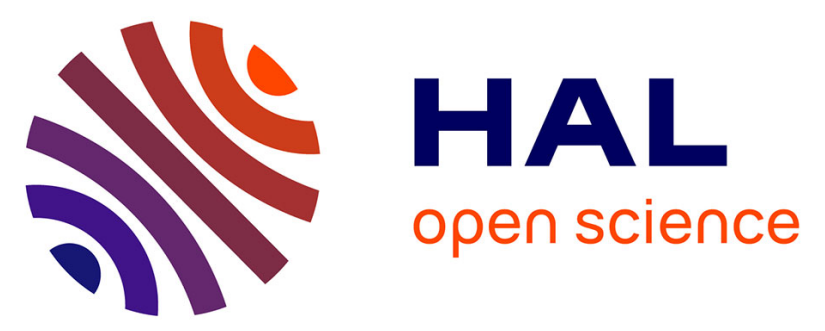

\title{
TERT promoter mutations identify a high-risk group in metastasis-free advanced thyroid carcinoma
}

Claire Bournaud, Françoise Descotes, Myriam Decaussin-Petrucci, Julien Berthiller, Christelle de La Fouchardière, Anne-Laure Giraudet, Mireille Bertholon-Gregoire, Philip Robinson, Jean-Christophe Lifante, Jonathan Lopez, et al.

\section{To cite this version:}

Claire Bournaud, Françoise Descotes, Myriam Decaussin-Petrucci, Julien Berthiller, Christelle de La Fouchardière, et al.. TERT promoter mutations identify a high-risk group in metastasis-free advanced thyroid carcinoma. European Journal of Cancer, 2019, 108, pp.41 - 49. 10.1016/j.ejca.2018.12.003 . hal-03486174

\section{HAL Id: hal-03486174 \\ https://hal.science/hal-03486174}

Submitted on 20 Dec 2021

HAL is a multi-disciplinary open access archive for the deposit and dissemination of scientific research documents, whether they are published or not. The documents may come from teaching and research institutions in France or abroad, or from public or private research centers.
L'archive ouverte pluridisciplinaire HAL, est destinée au dépôt et à la diffusion de documents scientifiques de niveau recherche, publiés ou non, émanant des établissements d'enseignement et de recherche français ou étrangers, des laboratoires publics ou privés.

\section{(ㄷ)(1) $\$$}

Distributed under a Creative Commons Attribution - NonCommerciall 4.0 International 
1 TERT promoter mutations identify a high-risk group in metastasis-free advanced 2 thyroid carcinoma.

3

4 Claire Bournaud ${ }^{1}$, Françoise Descotes ${ }^{2}$, Myriam Decaussin-Petrucci ${ }^{3,4}$, Julien Berthiller ${ }^{5}$, 5 Christelle de la Fouchardière ${ }^{6}$, Anne-Laure Giraudet ${ }^{7}$, Mireille Bertholon-Gregoire ${ }^{1}$, Philip 6 Robinson $^{8}$, Jean-Christophe Lifante ${ }^{9,10}$, Jonathan Lopez ${ }^{2,4}$, Françoise Borson-Chazot ${ }^{10,11}$

8 1. Hospices Civils de Lyon, Groupement Hospitalier Est, Service de Médecine Nucléaire, $9 \quad$ Bron cedex F-69677

2. Hospices Civils de Lyon, Groupement Hospitalier Sud, Service de Biochimie et Biologie

11 Moléculaire, Pierre Bénite cedex, F-69495

12 3. Hospices Civils de Lyon, Groupement Hospitalier Sud, Service d'Anatomie Pathologique, 13 Pierre Bénite cedex, F-69495

4. Université Lyon 1, Cancer Research Center of Lyon, INSERM1052 CNRS5286, Lyon F69008

5. Hospices Civils de Lyon, Groupement Hospitalier Est, Service d’Epidémiologie Clinique,

17 Pôle Information Médicale Evaluation Recherche, Bron cedex F-69677

6. Centre Léon Bérard, Department of Medical Oncology, 28 rue Laennec, Lyon cedex, F69373

7. Centre Léon-Bérard, Département de Médecine Nucléaire, 28, rue Laennec, Lyon cedex, F-

$21 \quad 69373$

22 8. Hospices Civils de Lyon, Direction de la Recherche Clinique et de l'Innovation, Lyon cedex, F-69437

9. Hospices Civils de Lyon, Groupement Hospitalier Sud, Service de Chirurgie Générale et

Endocrinienne, Pierre Bénite cedex, F-69495 
26 10. Hospices Civils de Lyon, Fédération d'Endocrinologie, Bron cedex F-69677

27 11. Université Lyon 1, HESPER EA 7425, Lyon F-69008

28

29 Corresponding author: Claire Bournaud, Hospices Civils de Lyon, Groupement Hospitalier

30 Est, Service de Médecine Nucléaire, 59 boulevard Pinel, F-69677 Bron cedex, France. Tel.

$31+33$ (0)4 723572 81; Fax: +33 (0)4 726813 33; mail:claire.bournaud-salinas@ chu-lyon.fr

32 


\section{ABSTRACT}

Background: TERT promoter mutations are associated with adverse clinicopathological characteristics in thyroid carcinomas and considered as a major indicator of poor outcome. Nevertheless, most studies have pooled heterogeneous types of thyroid carcinomas, and have been conducted retrospectively. We investigated the association between TERT promoter mutations and recurrence in a prospective series of 173 intermediate-to-high risk thyroid cancer patients.

Patients: Patients referred for radioiodine treatment after thyroidectomy for intermediate-tohigh risk differentiated thyroid carcinoma were included in a prospective observational study and tested for TERT promoter, BRAF, and RAS mutations of their primary tumours. We analysed the relationship between TERT promoter mutations and outcome.

Results: The prevalence of TERT promoter mutations was $20.2 \%(35 / 173)$ in the total population. It was significantly higher in tumours harbouring aggressive histological features (poorly differentiated carcinoma, tall cell variant of papillary cancer, or widely invasive follicular cancer) than in non-aggressive tumours: $32.7 \%(16 / 49)$ versus $15.3 \%(19 / 124 ; \mathrm{p}$ $=0.020)$. TERT promoter mutations were also strongly associated with age $\geq 45$ years $(\mathrm{p}=0.005), \mathrm{pT} 4$ stage $(\mathrm{p}=0.015)$, metastatic disease $(\mathrm{p}=0.014)$, and extra-thyroidal extension $(\mathrm{p}=0.002)$. TERT promoter mutations were associated with poor outcome in the total population $(\mathrm{p}<0.001)$ but not in the subgroup of non-metastatic patients $(\mathrm{p}=0.051)$. However, they were associated with a worse outcome in patients both free of metastases and devoid of aggressive histological features. Neither BRAF nor RAS mutations were associated with event-free survival in non-metastatic patients.

55 Conclusion: Although their prognostic value does not seem to overcome that of histology, TERT promoter mutations may help to better define the prognosis of localized thyroid cancer patients without aggressive histology. 


\section{Highlights}

61 TERT mutations are associated with clinicopathological adverse features, even in

62 intermediate-to-high-risk thyroid cancer.

63 In intermediate-to-high risk thyroid cancer, TERT mutations do not overcome the prognostic

64 value of histological features.

65 TERT mutations may be useful to identify high-risk patients among those without adverse 66 histological features.

67

68 Keywords

69 Thyroid cancer; TERT promoter mutations; prognostic factors

70

71 Acknowledgements

72 We would like to thank Celine Michaux, Florence Geiguer and Florence Morin for their 73 excellent technical support, and Armelle Delahaye for her help in collecting data. This work 74 was supported by a grant from la Ligue Nationale contre le Cancer.

75 Role of the funding source : funding of laboratory technician.

76

77 


\section{Introduction}

79 Despite overall excellent prognosis, it is estimated that up to $20 \%$ of thyroid carcinomas relapse and 5-10\% will evolve to metastases [1]. This proportion is increased among some subgroups of carcinomas including aggressive histological variants such as poorly differentiated thyroid carcinomas (PDTC) or tall cell papillary carcinomas (TCPTC)[2,3]. The development of targeted therapies has led to increased interest in the identification of molecular alterations present in thyroid cancer and their potential prognostic impact. BRAF and RAS mutations have been the most extensively studied. BRAF mutation is associated with advanced forms of thyroid cancer but is nowadays understood not to be an independent prognostic factor [4]. TERT promoter mutations have been described as predictive of poor prognosis in Differentiated Thyroid Carcinoma (DTC) in most published studies [5-11], except in micropapillary cancer[12]. Nevertheless, these studies pooled heterogeneous types of thyroid carcinomas, and most have been conducted retrospectively. The aim of the present study was to analyse the prognostic value of TERT mutations in a prospective series of intermediate-to-high risk thyroid carcinoma patients.

\section{Patients and Methods}

\subsection{Patients}

A total of 173 consecutive patients (105 females and 68 males; mean \pm standard deviation (SD) age 50.8 \pm 17.5 years, range:18-93) with DTC (pT3 $\geq 20 \mathrm{~mm}$, pT4 or M1 according to the 2004 WHO classification) referred for radioiodine (RAI) therapy after thyroidectomy in 1 of the 2 nuclear medicine hospital departments of Lyon, France, were included between 2010 and 2013 in a prospective observational study and tested for molecular alterations of their primary tumour. The local ethics committee approved the study. Written informed consent for molecular analysis was obtained at the time of surgery. 
103 In accordance with international guidelines available at the time of surgery[13], all patients

104 had undergone a total or near total thyroidectomy, associated with lymph node dissection 105 depending on the results of preoperative ultrasonography (US). After RAI administration, 106 follow-up and subsequent treatments, if necessary, were conducted as recommended by the

107 American Thyroid Association (ATA) 2009 guidelines[13].

108 The patients were submitted to restaging procedures, as described by Tuttle et al.[14] and

109 modified in the ATA2016 guidelines [15] after a mean \pm SD delay of $15.6 \pm 6$ months. Patients

110 with excellent or indeterminate response to initial treatment were considered in remission,

111 whereas those with biochemical or structural incomplete response were considered as having

112 persistent disease.

113 Subsequently, once-a-year for 5 years, the status of the patients was re-evaluated on the basis

114 of thyroglobulin (Tg) determination, cervical ultrasonography (US), and, if appropriate, other 115 imaging. No evidence of disease (NED) was defined by a suppressed $\mathrm{Tg}<1 \mu \mathrm{g} / \mathrm{l}$, no detectable $116 \mathrm{Tg}$ antibody (TgAb), and no structural evidence of disease[15]. In case of recurrent disease, 117 the type of relapse was specified: biological or morphological, local or metastatic. Cases and 118 causes of death (from cancer or not) were recorded. The database also recorded every thyroid 119 specific treatment administered, allowing the identification of iodine refractory disease, as 120 defined by Schlumberger et al.[16].

\subsection{Tumour sample analyses}

123 All tumour samples were reviewed by a referent pathologist (MDP) and classified according 124 to the 2004 WHO classification [17]. Patients with aggressive histological features including 125 PDTC, TCPTC, and widely invasive follicular carcinomas were pooled and compared to 126 those with non-aggressive tumours. 
127 DNA was isolated from formalin-fixed paraffin-embedded tissue blocks of tumour thyroid

128 tissue, using the QIAamp-DNA-FFPE tissue kit on a QIAcube instrument (Qiagen, Hilden,

129 Germany). Mutations of TERT promoter were analysed using nested PCR and sequencing as

130 previously described[18]. Mutations of BRAF exon 15, NRAS exon 3, HRAS exon 3, were

131 screened using real-time PCR and fluorescence high-resolution melting curve analysis on a

132 LightCycler480 instrument (RocheDiagnostics, Vienna, Austria). Positive samples were

133 confirmed by Sanger sequencing[19].

\subsection{Statistical analysis}

136 Categorical variables are expressed as number (n) and percentage, quantitative variables are

137 expressed as mean \pm SD. The hypothesis of normal distribution of quantitative variables was

138 tested using the Kolmogorov-Smirnov test and graphically confirmed with a histogram.

139 Categorical variables were compared using the $\mathrm{Chi}^{2}$ test or Fisher's exact test when the

140 conditions of application of $\mathrm{Chi}^{2}$ test were not met. Quantitative variables were compared

141 between groups using Student's t test after verification of equality of variances when data

142 were normally distributed, and with the Wilcoxon nonparametric test when the hypothesis of

143 normality of distribution was not verified.

144 Survival curves were obtained using a Kaplan-Meier model and compared using the Log-

145 Rank test. Event was defined as diagnosis with metastasis or refractory disease, or death

146 during follow-up. Event-free survival was determined between date of evaluation and date of

147 event or date of last known status.

148 Prognostic factors of event were determined using a Cox model after verification of the 149 proportionality of risk hypothesis, first in a univariate analysis, and, if appropriate, in 150 multivariate analysis including factors found significant in univariate analysis and adjusted on 151 age. 
152 The statistical tests were two-tailed and the level of significance was set to $5 \%(\mathrm{p}<0.05)$.

153 Statistical analyses were conducted using SAS v9.4 (SAS Institute Inc, Cary, NC, USA).

\section{Results}

\subsection{Clinical presentation and follow-up of the cohort}

157 Clinical and histopathological data are presented in Table 1. Eighty-two per cent of patients 158 (142/173) had a well-differentiated thyroid cancer from papillary (PTC) or follicular (FTC) type and 18\% (31/173) a PDTC. Among the 133 PTC, most were classical or follicular variant and 14 had tall cell features. Four of the 9 FTC had widely invasive features. As a whole, 49 tumours had aggressive histological features.

162 After thyroidectomy, 165 patients received a fixed activity of $3.7 \mathrm{GBq}$ of radioiodine; 8

163 received a lower dose (range: $1.1-1.85 \mathrm{GBq}$ ) either because of altered renal function, or

164 because of large remnant. Post-therapeutic whole-body scan (WBS) found extra-cervical 165 uptake indicative of metastatic disease in 30 patients, including the 7 whose cancer had been 166 diagnosed on a metastasis: metastatic sites were lung $(n=20)$, bones $(n=14)$, liver $(n=2)$, and 167 brain $(\mathrm{n}=1)$.

168 In total, $76.3 \%$ of the cohort had an excellent $(n=107)$ or indeterminate $(n=25)$ response to 169 therapy whereas $23.7 \%$ had a biochemical $(n=7)$ or structural $(n=34)$ incomplete response 170 (Table 2). Among the 30 initially metastatic patients, 8 (26.7\%) had an excellent response to 171 therapy, $5(16.7 \%)$ an indeterminate response, and $17(56.7 \%)$ remained with structural

172 disease. Among the 143 non-metastatic patients, 99 (69.2\%) had an excellent response to 173 therapy, $20(13.9 \%)$ an indeterminate response, $7(4.8 \%)$ a biochemically incomplete 174 response, and $17(11.8 \%)$ a structurally incomplete response.

175 Regarding treatments, $114(65.9 \%)$ patients received a single course of RAI after surgery, 176 whereas $59(34.1 \%)$ received at least one subsequent course of RAI either for initially 
177 metastatic disease or for subsequent relapse. Twenty patients were reoperated, for cervical

178 disease $(n=14)$ or for bone metastases $(n=6)$. Local treatments were administered to 12

179 patients (external beam $n=8$, cryotherapy $n=2$, cementoplasty $n=1$, radiofrequency $n=1$ ) and

18010 patients received systemic treatments (chemotherapy $n=2$ and tyrosine kinase inhibitors

$181 \mathrm{n}=8)$.

182 At the end of follow-up, after a mean \pm SD delay of $46 \pm 19$ months, 28 patients (16.2\%) were

183 metastatic $(\mathrm{n}=22$, including 14 with refractory disease) or had died from thyroid cancer $(\mathrm{n}=6$;

184 Table 2). Among the 132 patients with excellent or indeterminate response at the time of 185 restaging, $119(90.1 \%)$ remained in remission. Twelve $(9.1 \%)$ experienced relapse from 186 thyroid carcinoma, 5 with isolated elevated Tg levels, 3 with cervical recurrence, and 4 with 187 metastatic disease. One patient died from pulmonary embolism.

188

\subsection{Prevalence of mutations.}

190 A TERT mutation was found in 35 (C228T, $n=31$; C250T, $n=4)$ of the 173 tumours $(20.2 \%)$.

191 There was a trend toward greater prevalence of TERT mutations in PDTC $(10 / 31,32.3 \%)$

192 than in DTC $(25 / 142,17.6 \% ; \mathrm{p}=0.084)$. The prevalence of TERT mutations was $32.7 \%$

193 (16/49) in tumours with aggressive histological features, and this was significantly higher than

194 in non-aggressive tumours $(15.3 \%, 19 / 124 ; \mathrm{p}=0.020)$.

195 A BRAF mutation was found in 50 tumours (28.9\%). Prevalence was $34.5 \%$ (49/142) in

196 DTC, and this was significantly higher than in PDTC $(1 / 31,3.2 \%$; $<<0.001)$; there was no 197 significant difference between aggressive $(12 / 49,24.5 \%)$ and non-aggressive tumours $198(38 / 124,30.6 \% ; \mathrm{p}=0.462)$.

199 A RAS mutation was found in 27 (NRAS, $n=17$; HRAS, $n=10$ ) tumours (15.6\%). RAS 200 mutations were identified in $12.0 \%$ (17/142) of DTC tumours, and this was significantly 201 lower than in PDTC tumours $(32.3 \%, 10 / 31 ; \mathrm{p}=0.011)$. 
Co-occurrence of BRAF and TERT mutations were found in 13 tumours (7.5\%) and of TERT

203 and RAS in $9(5.2 \%) ; 22$ out of the 35 (62.8\%) tumours with a TERT mutation also had 204 another mutation.

\subsection{Relationship between TERT mutations, clinicopathological features, and outcome.}

207 The presence of a TERT mutation was significantly more frequent among patients aged $\geq 45$ 208 years at time of surgery $(\mathrm{p}=0.005)$, pT4 stage $(\mathrm{p}=0.015)$, metastatic disease $(\mathrm{p}=0.014)$, extra209 thyroidal extension (ETE, $\mathrm{p}=0.002$; Table 1), occurrence of extra-cervical radioiodine uptake 210 on post-therapeutic WBS ( $\mathrm{p}=0.011$ ) or of structural incomplete response at restaging (Table $2112)$.

212 Among M0 patients, the proportion of excellent/indeterminate response to initial treatment 213 was higher in TERT wild-type patients $(86.6 \%)$ than in those with mutated TERT (66.7\%; $214 \mathrm{p}=0.042$, Table 2). At last follow-up, the proportion of NED patients was higher in TERT 215 wild-type M0 patients (79.1\%) than in TERT mutated M0 patients (54.2\%; p=0.003). The 216 proportion of metastatic or dead from thyroid carcinoma patients was lower in TERT wild217 type M0 patients (6.7\%) than in TERT mutated patients (29.2\%).

218 The final status of initially metastatic patients did not differ according to TERT status: 9/19 219 (47.4\%) of TERT wild-type achieved NED as compared to 3/11 (27.3\%) TERT mutated; and 6/19 (31.6\%) of TERT wild-type patients remained metastatic or had died from thyroid 221 carcinoma, versus 7/11 (63.7\%) of TERT mutated patients.

222 Among patients with aggressive histology, the proportion of remission and metastases were 223 similar irrespective of TERT mutation status as presented in Table 3. In the group of patients 224 with non-aggressive histology $(n=124)$, the proportion of excellent or indeterminate response 225 to initial treatment $(\mathrm{p}=0.006)$ as well as the proportion of NED at the end of follow-up was 226 higher in TERT wild-type than in TERT mutated patients ( $\mathrm{p}=0.001$; Table 3$)$. 
229 In the total population (M0+M1), TERT mutations were significantly associated with poor 230 prognosis (Log-rank test, $\mathrm{p}<0.001$; Fig.1A); the difference did not remain statistically 231 significant when only M0 patients were considered (Log-rank test, p=0.051; Fig.1B. 232 Aggressive histological features were significantly associated with poor event-free survival 233 even among non metastatic patients (Log-rank test, $\mathrm{p}<0.001 ;$ Fig 2).

234 In non-metastatic patients, event-free survival was associated in univariate analysis with age 235 equal to 45 years or above at surgery $(\mathrm{p}=0.034)$, histological aggressive features $(\mathrm{p}<0.001)$ 236 and vascular invasion $(\mathrm{p}<0.001)$. Neither TERT, nor BRAF or RAS were associated with 237 event-free survival (Table 4). In multivariate analysis, histological aggressive features 238 remained significantly associated with worse event-free survival (Table 5).

239 TERT mutations were not significantly associated with event-free survival in M0 patients 240 with aggressive histology (Fig3A) but were strongly associated with this among M0 patients 241 with non-aggressive histological features (no event in the WT group; Fig.3B).

\section{Discussion}

244 In the present study, TERT mutations were found to be strongly associated with adverse 245 pathological features such as older age at surgery, aggressive histological features, pT4 stage, 246 metastatic disease, and extra-thyroidal extension, which is in accordance with the literature 247 [5-8,10,20-23]. TERT mutations were associated with poor outcome in the total population 248 but were not predictive of outcome in initially non-metastatic patients or among those 249 harbouring aggressive histologic features. Nevertheless, TERT mutations were strongly 250 associated with a poor outcome in patients free of metastases and devoid of aggressive 251 histological features. 
252 Patients included herein were selected on histological criteria (pT stage, size, or initial 253 metastatic spread) that, in our experience, are the most frequently observed among 254 radioiodine refractory patients. All were classified at either intermediate or high risk of 255 relapse according to the ATA2009 classification[13]. Importantly, response to initial 256 treatment as well as status at the end of follow-up were those expected in patients with such 257 clinical and histological features [14]. We therefore believe that this cohort is representative 258 of intermediate-to-high risk thyroid cancer patients. The mean duration of follow-up of 46 259 months seems acceptable, as it has been reported that more than $75 \%$ of papillary thyroid 260 carcinoma recurrence occurs within the first 5 years after initial treatment [24]. Furthermore, 261 by contrast with most published studies, this was a prospective cohort which may avoid some 262 classical biases.

263 TERT mutations were identified among a fifth of the tumours herein, a relatively high 264 proportion as compared to the pooled frequency of $14.3 \%$ in a recent meta-analysis[25], that 265 is explained by the selection of intermediate-to-high risk DTC. While it is well established 266 that PDTC more frequently harbour TERT mutations than differentiated carcinomas $267[10,21,26,27]$, the difference did not reach statistical significance in the present study. This 268 discrepancy may be attributed to the low number of PDTC, or to the relatively high 269 proportion of TCPTC, among which up to 30\% harbour TERT mutations [25]. Indeed, herein, 270 TERT mutations were significantly more frequent in tumours with aggressive histological 271 features than in non-aggressive tumours, a result that is concordant with the literature[21-23]. 272 BRAF mutation was initially identified as a major prognostic factor of papillary thyroid 273 carcinomas[28]. Herein, even in univariate analysis BRAF was not associated with event-free 274 survival. One potential explanation could be the relatively low prevalence of BRAF mutation 275 in the present study that pooled PTC, FTC, and PDTC. But it must also be underlined that the 
prognostic value of BRAF mutation has been questioned, some studies failing to demonstrate

277 that BRAF mutation was an independent prognostic factor[29].

278 Whereas most studies have evaluated the impact of TERT only on long-term outcome, finding 279 an increased risk of death and of radioiodine courses [10,30], the prospective design of the 280 present study allowed the analysis of the patient status at various times of follow-up. At the 281 time of restaging, only structural incomplete responses were considered, as it has been 282 reported by others that most patients with biological residual disease will finally evolve 283 without any relapse[31]. We found that TERT mutations were associated with incomplete 284 response to initial treatment and a lower probability of NED at the end of follow-up, even in 285 the subgroup of initially non-metastatic patients, a finding suggesting these patients need 286 reinforced monitoring and treatment. Penna et al.[23] recently found an association between 287 TERT mutations and both initial response to treatment or progression of structural disease among patients with aggressive variants of thyroid carcinomas, data not confirmed in our study. Nevertheless, their cohort differs from our subgroup of patients with aggressive histologic features in terms of definition (for example, we did not include follicular variant of 291 PTC displaying extensive invasion in that subgroup) and initial stage (54\% of their patients 292 were M1) and this may have influenced the results. In both studies, the number of patients with aggressive variants of thyroid cancer remains limited and prospective studies on larger 294 groups remain necessary.

295 In this study, the limited length of follow-up and the rarity of deaths precluded the analysis of 296 the influence of TERT mutations on overall survival. For the event-free survival analysis, 297 patients with metastatic disease at diagnosis were excluded. In univariate analysis older age at 298 diagnosis, vascular invasion and aggressive histology were significant indicators of higher 299 risk of event, but TERT mutations were not. The literature is currently divided as to the 300 association between TERT mutations and recurrence. For instance, there are studies that have 
301 found TERT mutations to be an independent predictor of poor outcome $[8,10,32,33]$.

302 Conversely, in accordance with the results presented herein other authors failed to 303 demonstrate that TERT mutations were an independent prognostic factor $[5,27,34]$. The 304 present study suggests the prognosis of patients with mutated tumours is not independent 305 from histological features. This was also suggested in one study in which TERT mutations 306 were associated with distant metastases in multivariate analysis, but only after exclusion of 307 vascular invasion which was not considered in the multivariate model[10]. Furthermore, in 308 patients with aggressive clinicopathological characteristics, the utility of molecular markers 309 can be questioned.

310 Interestingly, when focusing on M0 patients without aggressive histological features, the 311 subgroup of the cohort less prone to experience recurrence, TERT mutations were strongly 312 associated with a worse event-free survival. These results, in concordance with those recently 313 published by Xu et al. who report a small retrospective study of PTC with initially low-risk 314 histological features who developed metastases, suggest that TERT mutations should help to 315 identify patients requiring more intensive treatment and close follow-up [35].

\section{5. Conclusion}

318 The prognostic value of TERT mutations did not seem to overcome that of histology, but it 319 was associated with worse outcome in metastasis-free patients without aggressive histological 320 features and could thus help to identify a high-risk subset of patients who could benefit from 321 intensive treatment and follow-up.

325 Conflict of interest statement: None declared. 
[1] Schlumberger MJ. Papillary and follicular thyroid carcinoma. N Engl J Med 1998;338:297-306. doi:10.1056/NEJM199801293380506.

[2] Ibrahimpasic T, Ghossein R, Carlson DL, Nixon I, Palmer FL, Shaha AR, et al. Outcomes in patients with poorly differentiated thyroid carcinoma. J Clin Endocrinol Metab 2014;99:1245-52. doi:10.1210/jc.2013-3842.

[3] Moreno Egea A, Rodriguez Gonzalez JM, Sola Perez J, Soria Cogollos T, Parrilla Paricio P. Prognostic value of the tall cell variety of papillary cancer of the thyroid. Eur J Surg Oncol J Eur Soc Surg Oncol Br Assoc Surg Oncol 1993;19:517-21.

[4] Xing M, Haugen BR, Schlumberger M. Progress in molecular-based management of differentiated thyroid cancer. Lancet Lond Engl 2013;381:1058-69. doi:10.1016/S01406736(13)60109-9.

[5] Bullock M, Ren Y, O’Neill C, Gill A, Aniss A, Sywak M, et al. TERT promoter mutations are a major indicator of recurrence and death due to papillary thyroid carcinomas. Clin Endocrinol (Oxf) 2016;85:283-90. doi:10.1111/cen.12999.

[6] George JR, Henderson YC, Williams MD, Roberts DB, Hei H, Lai SY, et al. Association of TERT Promoter Mutation, But Not BRAF Mutation, With Increased Mortality in PTC. J Clin Endocrinol Metab 2015;100:E1550-1559. doi:10.1210/jc.2015-2690.

[7] Gandolfi G, Ragazzi M, Frasoldati A, Piana S, Ciarrocchi A, Sancisi V. TERT promoter mutations are associated with distant metastases in papillary thyroid carcinoma. Eur J Endocrinol 2015;172:403-13. doi:10.1530/EJE-14-0837.

[8] Xing M, Liu R, Liu X, Murugan AK, Zhu G, Zeiger MA, et al. BRAF V600E and TERT promoter mutations cooperatively identify the most aggressive papillary thyroid cancer with highest recurrence. J Clin Oncol Off J Am Soc Clin Oncol 2014;32:2718-26. doi:10.1200/JCO.2014.55.5094.

[9] Dettmer MS, Schmitt A, Steinert H, Capper D, Moch H, Komminoth P, et al. Tall cell papillary thyroid carcinoma: new diagnostic criteria and mutations in BRAF and TERT. Endocr Relat Cancer 2015;22:419-29. doi:10.1530/ERC-15-0057.

[10] Melo M, da Rocha AG, Vinagre J, Batista R, Peixoto J, Tavares C, et al. TERT promoter mutations are a major indicator of poor outcome in differentiated thyroid carcinomas. $\mathrm{J}$ Clin Endocrinol Metab 2014;99:E754-765. doi:10.1210/jc.2013-3734.

[11] Vinagre J, Almeida A, Pópulo H, Batista R, Lyra J, Pinto V, et al. Frequency of TERT promoter mutations in human cancers. Nat Commun 2013;4:2185. doi:10.1038/ncomms3185.

[12] de Biase D, Gandolfi G, Ragazzi M, Eszlinger M, Sancisi V, Gugnoni M, et al. TERT Promoter Mutations in Papillary Thyroid Microcarcinomas. Thyroid Off J Am Thyroid Assoc 2015;25:1013-9. doi:10.1089/thy.2015.0101.

[13] American Thyroid Association (ATA) Guidelines Taskforce on Thyroid Nodules and Differentiated Thyroid Cancer, Cooper DS, Doherty GM, Haugen BR, Hauger BR, Kloos RT, et al. Revised American Thyroid Association management guidelines for patients with thyroid nodules and differentiated thyroid cancer. Thyroid Off J Am Thyroid Assoc 2009;19:1167-214. doi:10.1089/thy.2009.0110.

[14] Tuttle RM, Tala H, Shah J, Leboeuf R, Ghossein R, Gonen M, et al. Estimating risk of recurrence in differentiated thyroid cancer after total thyroidectomy and radioactive iodine remnant ablation: using response to therapy variables to modify the initial risk estimates predicted by the new American Thyroid Association staging system. Thyroid Off J Am Thyroid Assoc 2010;20:1341-9. doi:10.1089/thy.2010.0178.

[15] Haugen BR, Alexander EK, Bible KC, Doherty GM, Mandel SJ, Nikiforov YE, et al. 2015 American Thyroid Association Management Guidelines for Adult Patients with 
Thyroid Nodules and Differentiated Thyroid Cancer: The American Thyroid Association Off J Am Thyroid Assoc 2016;26:1-133. doi:10.1089/thy.2015.0020.

[16] Schlumberger M, Brose M, Elisei R, Leboulleux S, Luster M, Pitoia F, et al. Definition and management of radioactive iodine-refractory differentiated thyroid cancer. Lancet Diabetes Endocrinol 2014;2:356-8. doi:10.1016/S2213-8587(13)70215-8.

[17] Citation:Edge SB, Byrd DR, Compton CC, Fritz AG, Greene FL, Trotti A 2010 Oncology for Medical Students n.d. https://wiki.cancer.org.au/oncologyformedicalstudents/Citation:Edge_SB,_Byrd_DR,_C ompton_CC,_Fritz_AG,_Greene_FL,_Trotti_A_2010 (accessed June 14, 2018).

[18] Descotes F, Kara N, Decaussin-Petrucci M, Piaton E, Geiguer F, Rodriguez-Lafrasse C, et al. Non-invasive prediction of recurrence in bladder cancer by detecting somatic TERT promoter mutations in urine. Br J Cancer 2017;117:583-7. doi:10.1038/bjc.2017.210.

[19] Decaussin-Petrucci M, Descotes F, Depaepe L, Lapras V, Denier M-L, Borson-Chazot F, et al. Molecular testing of BRAF, RAS and TERT on thyroid FNAs with indeterminate cytology improves diagnostic accuracy. Cytopathol Off J Br Soc Clin Cytol 2017;28:482-7. doi:10.1111/cyt.12493.

[20] Liu X, Qu S, Liu R, Sheng C, Shi X, Zhu G, et al. TERT promoter mutations and their association with BRAF V600E mutation and aggressive clinicopathological characteristics of thyroid cancer. J Clin Endocrinol Metab 2014;99:E1130-1136. doi:10.1210/jc.2013-4048.

[21] Landa I, Ganly I, Chan TA, Mitsutake N, Matsuse M, Ibrahimpasic T, et al. Frequent somatic TERT promoter mutations in thyroid cancer: higher prevalence in advanced forms of the disease. J Clin Endocrinol Metab 2013;98:E1562-1566. doi:10.1210/jc.2013-2383.

[22] Liu X, Bishop J, Shan Y, Pai S, Liu D, Murugan AK, et al. Highly prevalent TERT promoter mutations in aggressive thyroid cancers. Endocr Relat Cancer 2013;20:603-10. doi:10.1530/ERC-13-0210.

[23] Penna GC, Pestana A, Cameselle JM, Momesso D, de Andrade FA, Vidal APA, et al. TERTp mutation is associated with a shorter progression free survival in patients with aggressive histology subtypes of follicular-cell derived thyroid carcinoma. Endocrine 2018;61:489-98. doi:10.1007/s12020-018-1642-0.

[24] Durante C, Montesano T, Torlontano M, Attard M, Monzani F, Tumino S, et al. Papillary thyroid cancer: time course of recurrences during postsurgery surveillance. $\mathrm{J}$ Clin Endocrinol Metab 2013;98:636-42. doi:10.1210/jc.2012-3401.

[25] Su X, Jiang X, Wang W, Wang H, Xu X, Lin A, et al. Association of telomerase reverse transcriptase promoter mutations with clinicopathological features and prognosis of thyroid cancer: a meta-analysis. OncoTargets Ther 2016;9:6965-76. doi:10.2147/OTT.S116594.

[26] de la Fouchardière C, Decaussin-Petrucci M, Berthiller J, Descotes F, Lopez J, Lifante JC, et al. Predictive factors of outcome in poorly differentiated thyroid carcinomas. Eur J Cancer Oxf Engl 1990 2018;92:40-7. doi:10.1016/j.ejca.2017.12.027.

[27] Qasem E, Murugan AK, Al-Hindi H, Xing M, Almohanna M, Alswailem M, et al. TERT promoter mutations in thyroid cancer: a report from a Middle Eastern population. Endocr Relat Cancer 2015;22:901-8. doi:10.1530/ERC-15-0396.

[28] Xing M, Westra WH, Tufano RP, Cohen Y, Rosenbaum E, Rhoden KJ, et al. BRAF mutation predicts a poorer clinical prognosis for papillary thyroid cancer. J Clin Endocrinol Metab 2005;90:6373-9. doi:10.1210/jc.2005-0987. 
[29] Kim TY, Kim WB, Rhee YS, Song JY, Kim JM, Gong G, et al. The BRAF mutation is useful for prediction of clinical recurrence in low-risk patients with conventional papillary thyroid carcinoma. Clin Endocrinol (Oxf) 2006;65:364-8. doi:10.1111/j.13652265.2006.02605.x.

[30] Kim TH, Ki C-S, Kim HS, Kim K, Choe J-H, Kim J-H, et al. Refining Dynamic Risk Stratification and Prognostic Groups for Differentiated Thyroid Cancer With TERT Promoter Mutations. J Clin Endocrinol Metab 2017;102:1757-64. doi:10.1210/jc.20163434.

[31] Vaisman F, Momesso D, Bulzico DA, Pessoa CHCN, Dias F, Corbo R, et al. Spontaneous remission in thyroid cancer patients after biochemical incomplete response to initial therapy. Clin Endocrinol (Oxf) 2012;77:132-8. doi:10.1111/j.13652265.2012.04342.x.

[32] Song YS, Lim JA, Choi H, Won J-K, Moon JH, Cho SW, et al. Prognostic effects of TERT promoter mutations are enhanced by coexistence with BRAF or RAS mutations and strengthen the risk prediction by the ATA or TNM staging system in differentiated thyroid cancer patients. Cancer 2016;122:1370-9. doi:10.1002/cncr.29934.

[33] Kim TH, Kim Y-E, Ahn S, Kim J-Y, Ki C-S, Oh YL, et al. TERT promoter mutations and long-term survival in patients with thyroid cancer. Endocr Relat Cancer 2016;23:813-23. doi:10.1530/ERC-16-0219.

[34] Myung JK, Kwak BK, Lim JA, Lee M-C, Kim MJ. TERT Promoter Mutations and Tumor Persistence/Recurrence in Papillary Thyroid Cancer. Cancer Res Treat Off J Korean Cancer Assoc 2016;48:942-7. doi:10.4143/crt.2015.362.

[35] Xu B, Tuttle RM, Sabra MM, Ganly I, Ghossein R. Primary Thyroid Carcinoma with Low-Risk Histology and Distant Metastases: Clinicopathologic and Molecular Characteristics. Thyroid Off J Am Thyroid Assoc 2017;27:632-40. doi:10.1089/thy.2016.0582. 
Figure 1

A)

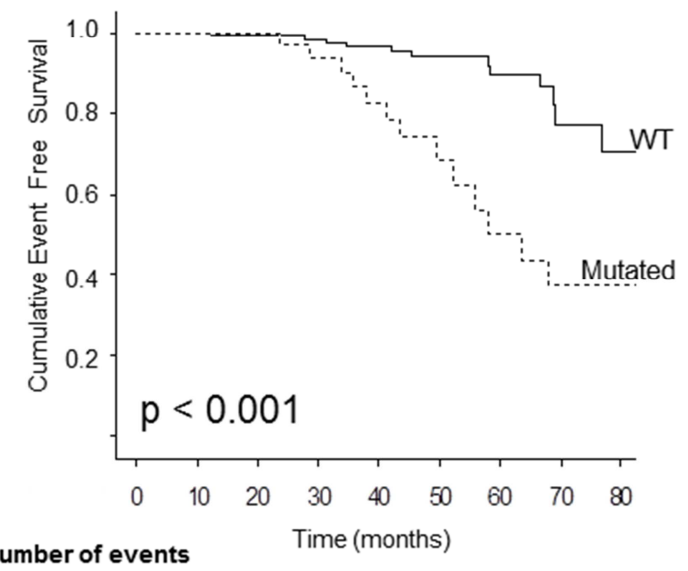

$\begin{array}{lllllllrrr}\text { Mutated } & - & 0 & 0 & 2 & 5 & 8 & 11 & 13 & 13 \\ \text { WT } & - & 0 & 1 & 2 & 4 & 6 & 8 & 11 & 12\end{array}$

Number at risk

$\begin{array}{cccccccccc}\text { Mutated } & 35 & 35 & 34 & 27 & 20 & 12 & 8 & 6 & 2 \\ & 138 & 136 & 125 & 107 & 86 & 61 & 40 & 16 & 8\end{array}$ WT

B)

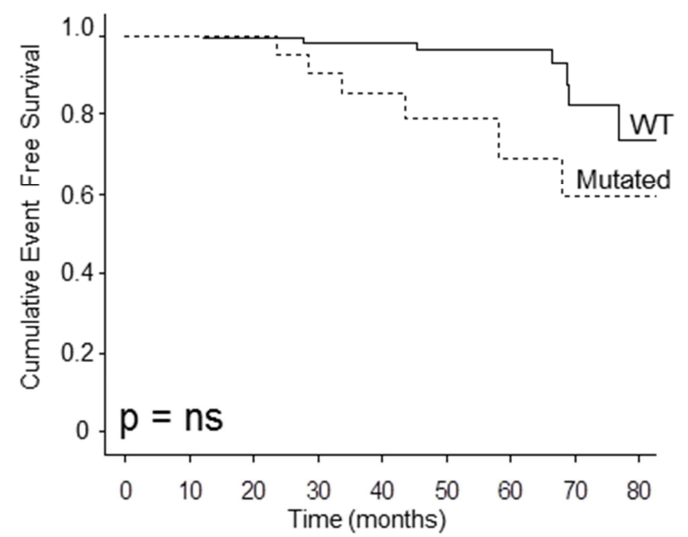

Number of events

$\begin{array}{lccccccccc}\text { Mutated } & - & 0 & 0 & 2 & 3 & 4 & 5 & 6 & 6 \\ \begin{array}{l}\text { WT } \\ \text { Number at risk }\end{array} & 0 & 1 & 2 & 2 & 3 & 3 & 6 & 7 \\ \begin{array}{l}\text { Mutated } \\ \text { WT }\end{array} & 24 & 24 & 24 & 18 & 14 & 9 & 7 & 6 & 2 \\ & 119 & 117 & 109 & 92 & 74 & 53 & 35 & 14 & 7\end{array}$


Figure 2.

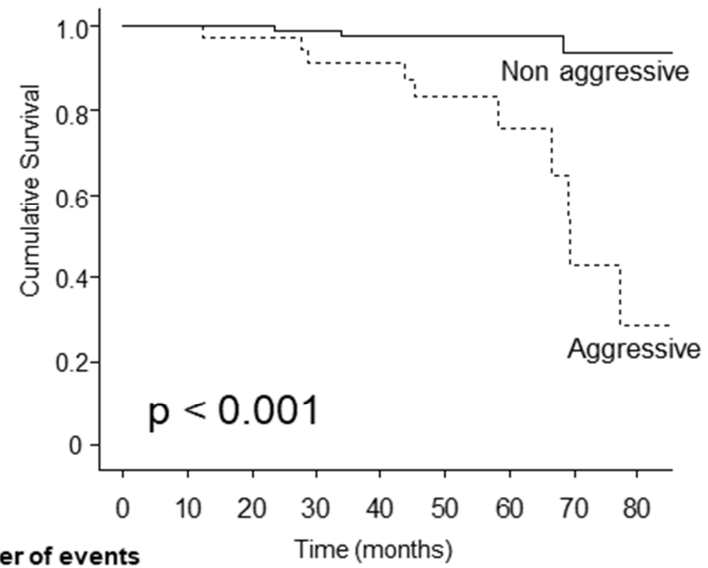

Number of events

$\begin{array}{llllllllll}\text { Aggressive } & - & 0 & 1 & 3 & 3 & 5 & 6 & 9 & 10\end{array}$

Number at risk

$\begin{array}{llllllllll}\text { Aggressive } & 38 & 37 & 35 & 29 & 24 & 15 & 10 & 4 & 2\end{array}$

$\begin{array}{lllllllll}\text { Non aggressive } & 105 & 104 & 97 & 81 & 64 & 47 & 32 & 16\end{array}$ 
Figure 3

\section{A)}

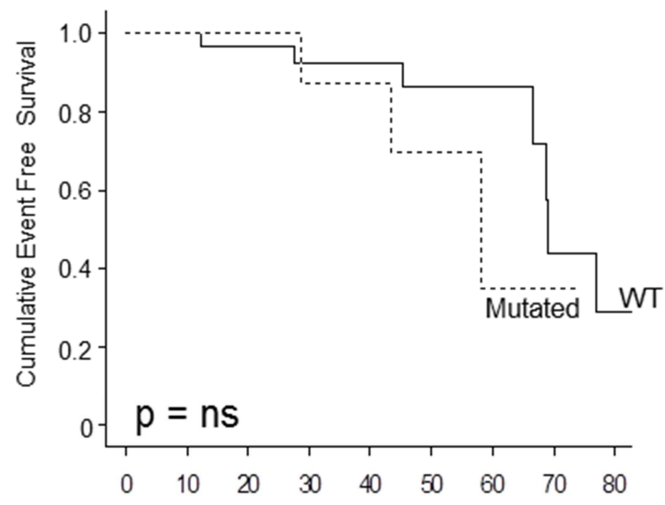

Number of events

$\begin{array}{llllllllll}\text { Mutated } & - & 0 & 0 & 1 & 1 & 2 & 3 & 3 & 3 \\ \text { WT } & - & 0 & 1 & 2 & 2 & 3 & 3 & 6 & 7\end{array}$

\section{Number at risk}

$\begin{array}{lccccccccc}\text { Mutated } & 9 & 9 & 9 & 7 & 5 & 2 & 1 & 1 & 0 \\ \text { WT } & & & \end{array}$

$\begin{array}{llllllllll}\text { WT } & 29 & 28 & 26 & 22 & 19 & 13 & 9 & 3 & 2\end{array}$

B)

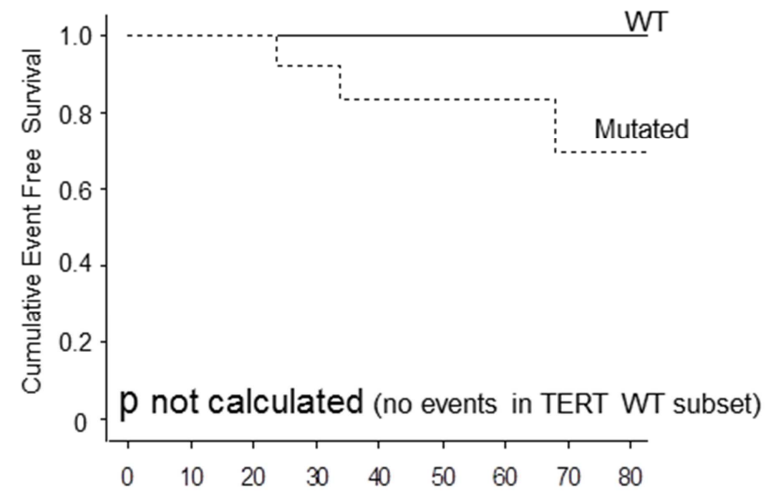

Number of events

$\begin{array}{llllllllll}\text { Mutated } & - & 0 & 0 & 1 & 2 & 2 & 2 & 3 & 3 \\ \text { WT } & - & 0 & 0 & 0 & 0 & 0 & 0 & 0 & 0\end{array}$

\section{Number at risk}

$\begin{array}{lllllccccc}\text { Mutated } & 15 & 15 & 14 & 11 & 9 & 7 & 6 & 5 & 2 \\ \text { WT } & 90 & 89 & 83 & 70 & 55 & 40 & 26 & 11 & 5\end{array}$ 
Table 1: Clinical and histopathological data

\begin{tabular}{|c|c|c|c|c|}
\hline & $\begin{array}{c}\text { Total } \\
\mathbf{n}=\mathbf{1 7 3}\end{array}$ & $\begin{array}{c}\text { TERT wild-type } \\
n=138\end{array}$ & $\begin{array}{c}\text { TERT mutated } \\
n=35 \\
\end{array}$ & $\mathbf{p}$ \\
\hline Sex, female, n (\%) & $105(60.7)$ & $86(62.3)$ & $19(54.3)$ & $0.385^{\circ}$ \\
\hline Age at surgery, $\mathrm{n}(\%)$ & & & & $0.005^{\mathrm{a}}$ \\
\hline$<45$ years & $71(41.0)$ & $64(46.4)$ & $7(20.0)$ & \\
\hline$\geq 45$ years & $102(59.0)$ & $74(53.6)$ & $28(80.0)$ & \\
\hline Histological features, $\mathrm{n}(\%)$ & & & & $0.011^{\mathrm{a}}$ \\
\hline Non-aggressive & $124(71.7)$ & $105(76.1)$ & $19(54.3)$ & \\
\hline Aggressive & $49(28.3)$ & $33(23.9)$ & $16(45.7)$ & \\
\hline Initial pT stage (M0 patients), n (\%) & & & & $0.015^{\mathrm{b}}$ \\
\hline pT3 & 136 & $116(97.5)$ & $20(14.7)$ & \\
\hline pT4 & 7 & $3(42.9)$ & $4(57.1)$ & \\
\hline Initial M stage, $\mathrm{n}(\%)$ & & & & $0.014^{\mathrm{a}}$ \\
\hline M0 & $143(82.7)$ & $119(86.2)$ & $24(68.6)$ & \\
\hline M1 & $30(17.3)$ & $19(13.8)$ & $11(31.4)$ & \\
\hline Tumour size $(\mathrm{cm})$, mean \pm SD & $4.15 \pm 1.9$ & $4.06 \pm 1.8$ & $4.51 \pm 2.1$ & $0.205^{\mathrm{c}}$ \\
\hline Extra-thyroidal Extension, n (\%) & & & & $0.002^{\mathrm{a}}$ \\
\hline Yes & $92(53.8)$ & $65(47.8)$ & $27(77.1)$ & \\
\hline No & $79(46.2)$ & $71(52.2)$ & $8(22.9)$ & \\
\hline Quality of Resection, n (\%) & & & & $0.100^{\circ}$ \\
\hline R0 & $136(84.0)$ & $113(86.3)$ & $23(74.2)$ & \\
\hline $\mathrm{R} 1-\mathrm{R} 2$ & $26(16.0)$ & $18(13.7)$ & $8(25.8)$ & \\
\hline Vascular Embols invasion, $\mathrm{n}(\%)$ & & & & $0.438^{\mathrm{a}}$ \\
\hline No & $105(65.2)$ & $86(66.7)$ & $19(59.4)$ & \\
\hline Yes & $56(34.8)$ & $43(33.3)$ & $13(40.6)$ & \\
\hline
\end{tabular}

${ }^{\mathrm{a}} \mathrm{Chi}^{2}$ test, ${ }^{\mathrm{b}}$ Fisher's exact test, ${ }^{\mathrm{c}} \mathrm{W}$ ilcoxon test 
Table 2: Results of post-therapeutic whole-body scan (post-Tx WBS) and follow-up.

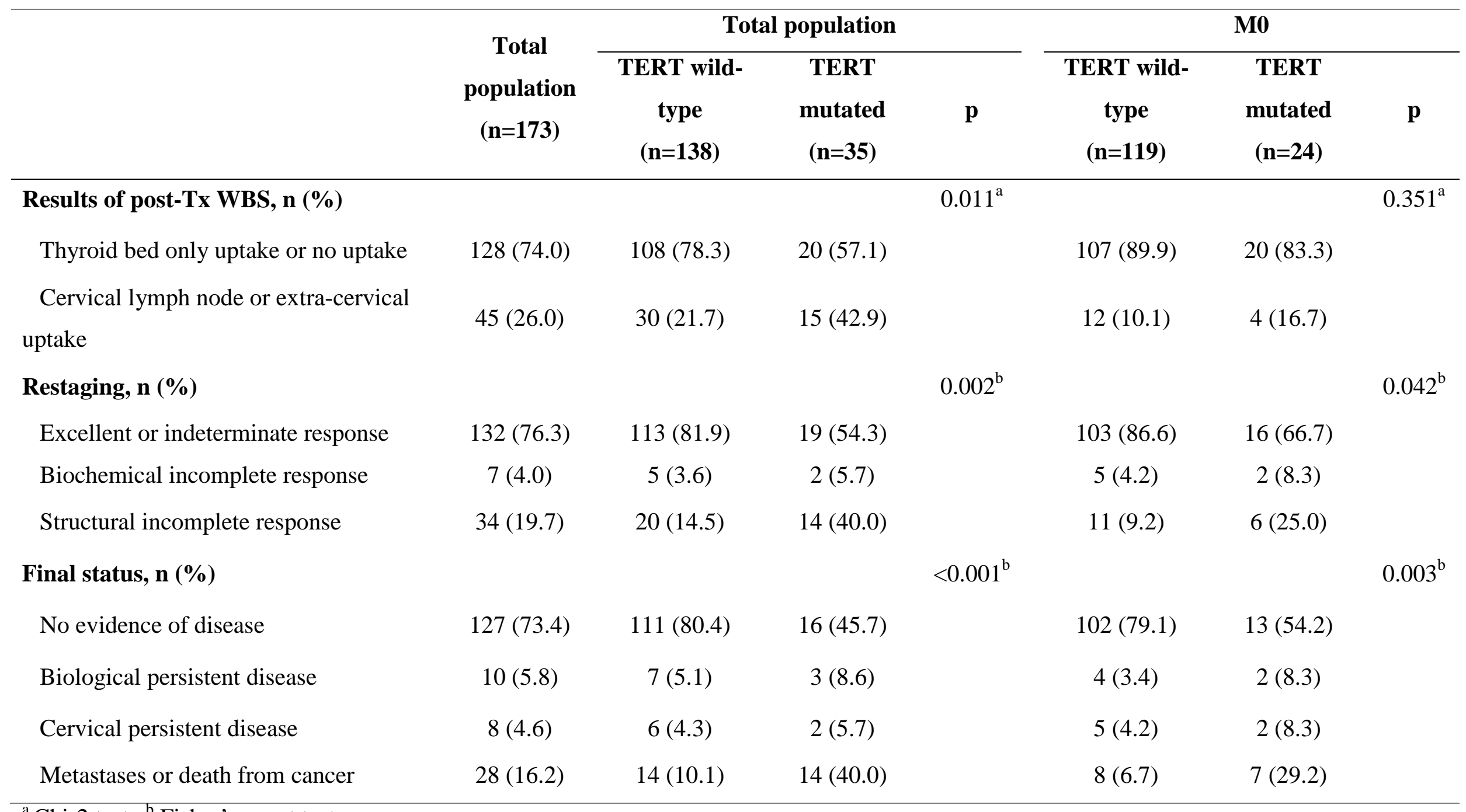

${ }^{\mathrm{a}}$ Chi-2 test ${ }^{\mathrm{b}}$ Fisher's exact test 
Table 3: Response to treatment according to histology and TERT promoter mutation status.

\begin{tabular}{|c|c|c|c|c|c|c|}
\hline & \multicolumn{3}{|c|}{ Aggressive histology } & \multicolumn{3}{|c|}{ Non-aggressive histology } \\
\hline & $\begin{array}{c}\text { Non-mutated } \\
(\mathbf{n}=33)\end{array}$ & $\begin{array}{c}\text { Mutated } \\
(n=16)\end{array}$ & $\mathbf{p}^{*}$ & $\begin{array}{l}\text { Non-mutated } \\
\qquad(n=105)\end{array}$ & $\begin{array}{c}\text { Mutated } \\
(n=19)\end{array}$ & $\mathbf{p}^{*}$ \\
\hline Restaging, n (\%) & & & 0.410 & & & 0.006 \\
\hline Excellent or indeterminate response & $22(66.7)$ & $8(50.0)$ & & $91(86.7)$ & $11(57.9)$ & \\
\hline Biochemical incomplete response & $1(3.0)$ & $1(6.3)$ & & $4(3.8)$ & $1(5.3)$ & \\
\hline Structural incomplete response & $10(30.3)$ & $7(43.8)$ & & $10(9.5)$ & $7(36.8)$ & \\
\hline Final status, $\mathbf{n}(\%)$ & & & 0.057 & & & 0.001 \\
\hline No evidence of disease & $20(60.6)$ & $5(31.3)$ & & $91(86.7)$ & $11(57.9)$ & \\
\hline Biological persistent disease & $0(0.0)$ & $2(12.5)$ & & $7(6.7)$ & $1(5.3)$ & \\
\hline Cervical persistent disease & $1(3.0)$ & $1(6.3)$ & & $5(4.8)$ & $1(5.3)$ & \\
\hline Metastases or death from cancer & $12(36.4)$ & $8(50.0)$ & & $2(1.9)$ & $6(31.6)$ & \\
\hline
\end{tabular}

* Fisher's exact test 
Table 4: Univariate analysis of prognostic factor for event-free survival among patients without metastasis.

\begin{tabular}{|c|c|c|c|c|c|}
\hline & $\mathbf{n}$ & Event & HR & $95 \% \mathrm{CI}$ & $\mathbf{p}$ \\
\hline \multicolumn{6}{|l|}{ Age } \\
\hline$<45$ & 64 & 1 & 1 & I & \\
\hline$\geq 45$ & 79 & 14 & 9.14 & $1.19-70.40$ & 0.034 \\
\hline \multicolumn{6}{|l|}{ Sex } \\
\hline Female & 83 & 8 & 1 & l & \\
\hline Male & 60 & 7 & 0.73 & $0.24-2.25$ & 0.584 \\
\hline \multicolumn{6}{|l|}{ Vascular embols invasion } \\
\hline No & 95 & 4 & 1 & l & \\
\hline Yes & 38 & 11 & 19.00 & $4.17-86.48$ & $<0.001$ \\
\hline \multicolumn{6}{|l|}{ Extra-thyroid extension } \\
\hline No & 65 & 4 & 1 & l & \\
\hline Yes & 76 & 10 & 2.48 & $0.76-8.13$ & 0.133 \\
\hline \multicolumn{6}{|l|}{ Histologic features } \\
\hline Non aggressive & 105 & 4 & 1 & I & \\
\hline Aggressive & 38 & 11 & 10.32 & $2.86-37.25$ & $<0.001$ \\
\hline \multicolumn{6}{|l|}{ TERT } \\
\hline Wild-type & 119 & 8 & 1 & l & \\
\hline Mutation & 24 & 7 & 2.81 & $0.95-8.30$ & 0.061 \\
\hline \multicolumn{6}{|l|}{ BRAF } \\
\hline Wild-type & 95 & 11 & 1 & l & \\
\hline Mutation & 48 & 4 & 0.65 & $0.20-2.07$ & 0.461 \\
\hline \multicolumn{6}{|l|}{ TERT + BRAF } \\
\hline Both wild type & 82 & 7 & 1 & l & \\
\hline At least one mutation & 50 & 5 & 0.66 & $0.17-2.56$ & 0.549 \\
\hline Both mutation & 11 & 3 & 2.17 & $0.55-8.57$ & 0.270 \\
\hline \multicolumn{6}{|l|}{ RAS } \\
\hline Wild-type & 126 & 13 & 1 & / & \\
\hline Mutation & 17 & 2 & 1.08 & $0.24-4.87$ & 0.923 \\
\hline
\end{tabular}

Event includes metastasis, refractory disease and death. 
Table 5: Multivariate analysis of prognostic factor for event-free survival among patients without metastasis.

\begin{tabular}{lccccc}
\hline & $\mathbf{n}$ & Event & HR* & $\mathbf{9 5 \%}$ CI & p \\
\hline TERT & 119 & 8 & 1 & $/$ & \\
Wild-type & 24 & 7 & 2.50 & $0.81-7.69$ & 0.111 \\
Mutation & 105 & 4 & 1 & $/$ & \\
Histological features & 38 & 11 & 9.43 & $2.51-35.42$ & $<0.001$ \\
Non aggressive & & & & \\
Aggressive & & &
\end{tabular}

* ajusted on age in continuous variable. 